\title{
Can Wistar rats be used as the normotensive controls for nerve morphometry investigations in spontaneously hypertensive rats (SHR)?
}

\author{
Ratos Wistar podem ser utilizados como os controles normotensos dos ratos espontaneamente \\ hipertensos (SHR) em investigações morfométricas de nervos periféricos?
}

\author{
Luciana Sayuri Sanada', Marcelo Rodrigo Tavares"I, Milena Cardoso Maia Neubern'II, Helio Cesar Salgado ${ }^{\mathrm{IV}}$, Valéria Paula \\ Sassoli Fazan ${ }^{\mathrm{V}}$
}

${ }^{\mathrm{I}}$ Fellow Master degree, Department of Neuroscience and Behavioral Neurosciences, FMRP-USP, Ribeirao Preto-SP, Brazil. Responsible for acquisition and interpretation of data, statistical analysis.

IIFellow PhD degree, Assistant Professor, Physical Education Course, University Jose do Rosario Velano, UNIFENAS, Alfenas-MG, Brazil. Responsible for acquisition and interpretation of data.

III Graduate student, FMRP-USP, Ribeirao Preto-SP, Brazil. Responsible for acquisition and interpretation of data.

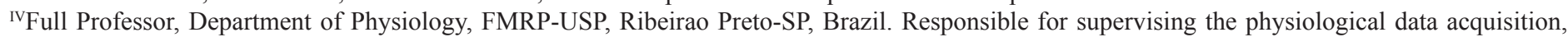
interpretation of the results.

vAssociate Professor, Head of Microscopy and Morphometry Laboratory, Department of Surgery and Anatomy, FMRP-USP, Ribeirao Preto-SP, Brazil. Responsible for concept design, intellectual and scientific content of the study, supervision of all phases of the study, manuscript writing, English language, critical revision.

\section{ABSTRACT}

PURPOSE: We compared the sural nerve morphology among Wistar (WR), Wistar-Kyoto (WKY) and Spontaneously hypertensive (SHR) rats, including the nerve fascicles and myelinated fibers morphometry.

METHODS: Age matched (20 weeks) female WR $(\mathrm{N}=6)$, WKY $(\mathrm{N}=6)$ and $\mathrm{SHR}(\mathrm{N}=7)$ had their right and left sural nerves removed, embedded in epoxy resin, and observed by light microscopy. Morphometric analysis was performed with the aid of computer software. RESULTS: Despite presenting the same age, WR were heavier than WKY and SHR, as were SHR compared to WKY. Systolic arterial pressure was higher in SHR compared to WR, but no differences between SHR and WKY or WR and WKY were observed. The sural nerves were morphometrically symmetric between proximal and distal segments on the same side and between sides in all strains with no differences in the myelinated fiber number. Schwann cell number and density were smaller in SHR and G ratio was larger in SHR, indicating that SHR have thinner myelinated fibers.

CONCLUSION: Sural nerve morphology is similar between WKY and WR, allowing the use of WR as the SHR controls in morphological investigations involving peripheral neuropathies.

Keywords: Sural Nerve. Rats, Inbred SHR. Rats, Inbred WKY. Nerve Fibers. Rats.

\section{RESUMO}

OBJETIVO: Comparar a morfologia do nervo sural em ratos Wistar (WR), Wistar Kyoto (WKY) e espontanemanete hipertensos (SHR), incluindo a morfometria dos fascículos e fibras mielínicas.

MÉTODOS: Os nervos surais direito e esquerdo de WR (N=6), WKY (N=6) e SHR $(\mathrm{N}=7)$, com 20 semanas de idade foram removidos e preparados para inclusão em resina epóxi e microscopia de luz. A morfometria foi realizada com o auxílio de um programa de computador.

RESULTADOS: Apesar de apresentarem a mesma idade, WR são mais pesados que os WKY e SHR. Ainda, SHR são mais pesados que os WKY. A pressão arterial sistólica foi significativamente maior nos SHR comparados aos WR, sem diferença entre WKY e SHR ou WR e WKY. Os nervos surais são morfometricamente simétricos entre segmentos proximal e distal e entre lados direto e esquerdo nas três diferentes linhagens, sem diferença no número de fibras mielínicas. O número e a densidade de células de Schwann foram menores e a razão $\mathrm{G}$ foi maior nos SHR, indicando a presença de fibras mielínicas com bainha mais fina.

CONCLUSÃO: A morfologia do nervo sural é semelhante ente WR e WKY, permitindo o uso de WR como controles dos SHR nas investigações envolvendo neuropatias periféricas.

Descritores: Nervo Sural. Ratos Endogâmicos SHR. Ratos Endogâmicos WKY. Fibras Nervosas. Ratos. 


\section{Introduction}

Spontaneously hypertensive rats (SHR) were first inbred from their normotensive ancestors, the Wistar-Kyoto rats (WKY) and it is expected that WKY would be used as the normotensive controls of SHR in diverse experimental protocols. Nevertheless, Wistar rats (WR) have been recently used as the SHR controls as often as the WKY ${ }^{1,2}$. The sural nerve is a sensory branch of the sciatic nerve widely used in nerve regeneration studies ${ }^{3}$. Reports on a possible hypertensive neuropathy are scanty in the literature ${ }^{4,5}$ and the authors have systematically used the WKY as the controls. However, the possibility of using other normotensive rat strain as the SHR control in of crescent interest, particularly when WKY are not readily or easily available. Information on the sural nerve normal morphology and morphometry is widely available in the literature for $\mathrm{WR}^{6}$, but not for SHR or WKY. We hypothesized that sural nerve morphology is similar between normotensive rat strains. To investigate this hypothesis, the present study was designed to compare the sural nerve morphology among WR, WKY and SHR, and took into consideration the fascicle area and diameter, as well as myelinated fiber number, density, area and diameter.

\section{Methods}

Experiments were performed in female WR $(\mathrm{N}=6)$, WKY $(\mathrm{N}=6)$ and SHR $(\mathrm{N}=7)$ born and raised in the animal care facility of the Department of Neurology, School of Medicine of Ribeirao Preto in a controlled environment (room temperature between $21-23{ }^{\circ} \mathrm{C}$, air humidity between 40 and $70 \%$ and dark/light cycle of $12 \mathrm{~h}$ ), housed in plastic cages (3-4 animals to a cage) with free access to tap water and rat chow throughout the experiments. All experimental procedures adhered to The Guide for the Care and Use of Laboratory Animals prepared by the National Academy of Sciences and published by the National Institutes of Health (Copyright $^{\circ} 1996$ by the National Academy of Sciences), and were approved by the Institutional Ethics Committee for Animal Research (CETEA - Comitê de Ética em Experimentação Animal). Effort was made to minimize the number of animals used.

Animals aged 20 weeks were placed in a chamber at $40{ }^{\circ} \mathrm{C}$ for $10 \mathrm{~min}$, and then transferred to a standard acrylic restrainer. A tail cuff and pulse sensor (IITC Life Science, Woodland Hills, CA) was positioned around the rat's tail and inflated until the complete disappearance of arterial pulse. Under continuous recording, the cuff pressure was decreased at a constant rate $(2-5 \mathrm{mmHg} / \mathrm{s})$ until the reestablishment of arterial pulse. Arterial pressure data was stored for posterior analysis.

Afterwards, animals were anesthetized with sodium pentobarbital (Nembutal, $40 \mathrm{mg} \mathrm{kg}$, i.p.) and perfused through the left ventricle first with a $0.05 \mathrm{M}$ phosphate-buffered saline solution, $\mathrm{pH} 7.4$ and then with a $2.5 \%$ glutaraldehyde solution in $0.1 \mathrm{M}$ cacodylate buffer, $\mathrm{pH}$ 7.2. Both right and left sural nerves, from their origin in the hip (5-7 $\mathrm{mm}$ distal to the greater trochanter) through their distal branching at the lateral malleolus level, were carefully dissected without stretching, removed in one piece and placed in the fixative solution for an additional 12 hour. They were washed in cacodylate buffer, $\mathrm{pH} \mathrm{7.2,} \mathrm{and} \mathrm{proximal} \mathrm{(close}$ to the origin) and distal (close to terminal branching) segments (of approximately $3 \mathrm{~mm}$ each) were cut and processed for epoxy resin embedding (EM Bed, EMbed-812 ${ }^{\circledR}$, Electron Microscopy Sciences, Hatfield, PA, USA) as described elsewhere ${ }^{7}$. Samples of all three experimental groups were histologically processed at once so that they were submitted to absolutely the same experimental conditions throughout the experiments.

Semithin $(0.2-0.3 \mu \mathrm{m}$ thick) transverse sections of the fascicles were stained with $1 \%$ toluidine blue and examined with the aid of an Axiophot II photomicroscope (Carl Zeiss, Jena, Germany). The images were sent via a digital camera (TK- 1270, JVC, Victor Company of Japan Ltd, Tokyo, Japan) to an IBM/PC where they were digitized. For the study of myelinated fibers, the endoneural space was observed with an optical set including an oil immersion lens $(100 \mathrm{x})$, optovar $(1.6 \mathrm{x})$, camera $(0.5 \mathrm{x})$ and an 8 $\mathrm{x}$ computerized magnification, which provided images with good resolution for morphometry.

The endoneural space was fully scanned without overlap of the microscopic fields, using an automatic motorized stage (Carl Zeiss, Jena, Germany). Scanning generated 9 to 17 microscopic fields of $640 \times 470$ pixels, which were used to count and automatically measure the myelinated fibers and their respective axons. Fibers at the upper and left edges of the microscopic fields were counted whereas those at the lower and right edges were not counted ("forbidden line") in order to avoid counting the same fiber twice. All myelinated fibers present in the endoneural space were counted. Morphometric parameters of the fascicles and myelinated fibers of sural nerve segments were obtained as described previously ${ }^{6,8}$. Briefly, the total number of myelinated fibers and the total number of Schwann cell nuclei present in each fascicle were counted. The area and lesser diameter of each fascicle (excluding the perineurium) as well as each myelinated fiber (defined by the axon and its respective myelin sheath excluding the Schwann cell nucleus when present) and respective axon (fiber excluding the myelin sheath) were measured with image analysis 
software (KS 400, Kontron 2.0, Eching Bei München, Germany). The lesser diameter better represents the diameter of a non-circular fascicle and fiber ${ }^{6,9}$. The myelinated fibers and Schwann cell nuclei densities were calculated. For myelinated fibers, both axonal diameter and total fiber diameter were automatically measured. The ratio between the two diameters, the $\mathrm{G}$ ratio (which indicates the degree of myelination ${ }^{10}$ ), was obtained. Myelin sheath area was calculated for each myelinated fiber measured. Histograms of population distribution of myelinated fibers and axons, separated into class intervals increasing by $1.0 \mu \mathrm{m}$ were constructed. Histograms of the $\mathrm{g}$ ratio distribution separated into class intervals increasing by 0.1 were also prepared. The investigators were blind to group identities throughout the experiments.

Morphometric data were tested for normal distribution by the Kolmogorov-Smirnov normality test followed by the Levene test for variance equivalence. If data presented a normal distribution and equivalent variance, comparisons were made between proximal and distal segments in the same group by paired Student's t-test. Otherwise, comparisons were made by Wilcoxon's non-parametric test for paired samples. For comparisons between right and left segments in the same group, normally distributed data were tested using the unpaired Student's t-test. Alternatively, comparisons were made by the Mann-Whitney non-parametric test. Comparisons between groups were made by one-way analysis of variance (ANOVA) followed by Holm-Sidak post hoc test for normally distributed data. Otherwise, the one-way analysis of variance (ANOVA) on Ranks, followed by Dunn's post hoc test was used. Comparisons between histograms were made by oneway analysis of variance (ANOVA) on Ranks provided that the distributions did not pass the normality test. Differences were considered significant if $\mathrm{p}<0.05$. Data are presented as mean \pm standard error of the mean (SEM).

\section{Results}

Body weight and systolic arterial pressure (SAP) of female WR, WKY and SHR, are shown in Figure 1. WR were significantly heavier than WKY and SHR as SHR were heavier compared to WKY. As expected, SAP was significantly higher in SHR compared to WR, but not different from WKY. Also, no differences on the SAP were observed between WR and WKY.
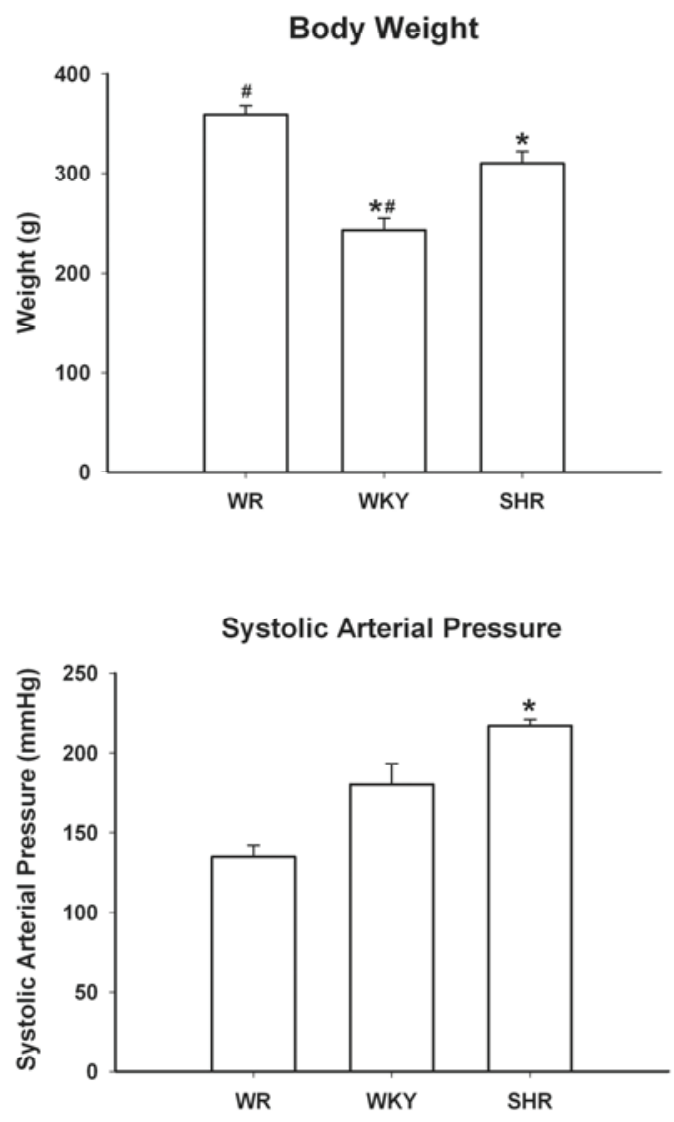

FIGURE 1 - Body weight (upper panel) and systolic arterial pressure (lower panel) average values for Wistar (WR), Wistar-Kyoto (WKY) and spontaneously hypertensive rats (SHR). * indicates difference compared to WR and \# indicates difference compared to SHR.

All sural nerves included in this study showed good preservation of structures and general morphological characteristics of the sural nerve fascicles of WR, WKY and SHR were similar to those previously described ${ }^{6,8}$. No endoneural morphological differences were observed between proximal and distal segments from the same side, and between the same segment (proximal or distal) from different sides, for all groups. However, the comparison between strains indicated that the sural nerves from SHR showed a larger number of collapsed blood vessels and/ or vessels with thickening of the wall (Figure 2). In addition, some myelinated fibers with degenerative signs were present in SHR. 


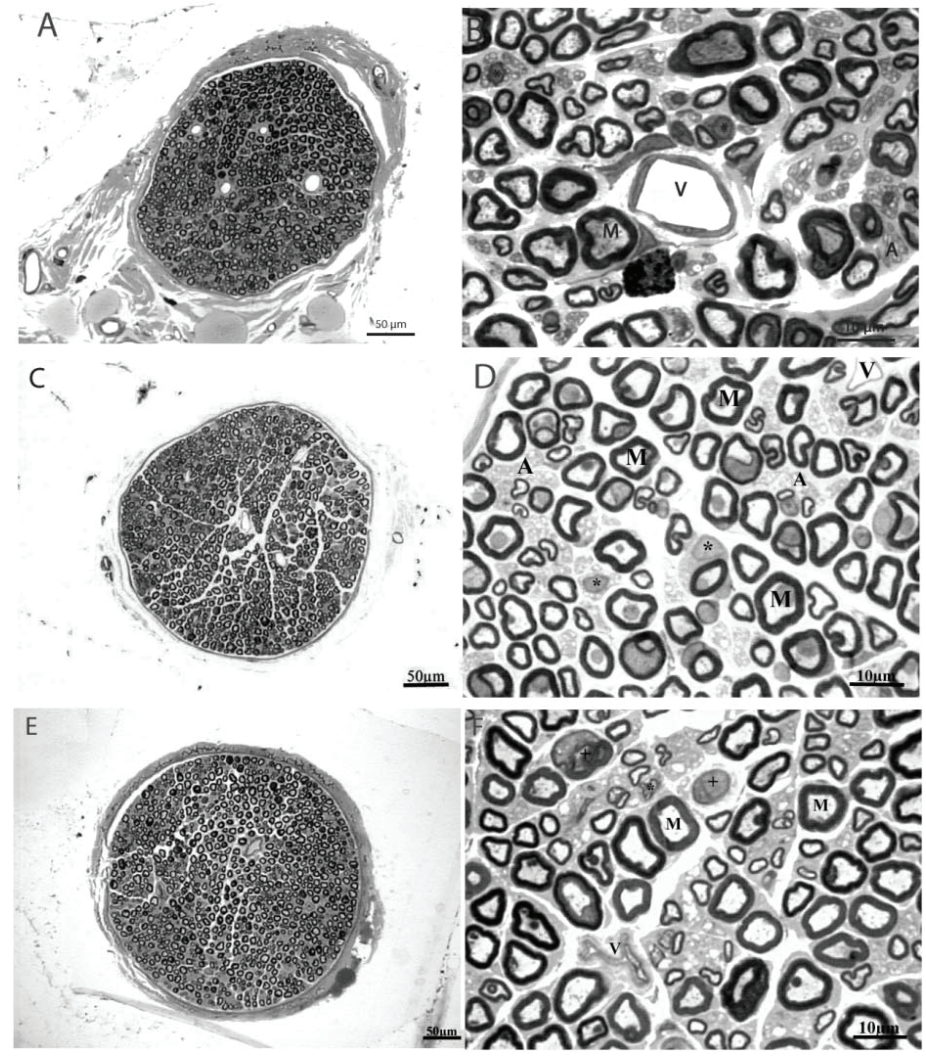

FIGURE 2 - Representative semithin cross section of the proximal segments of sural nerves of female Wistar (WR) (A), Wistar-Kyoto (WKY) (C) and spontaneously hypertensive rats (SHR) (E). Note that proximal segments of the sural nerves are monofasciculated, enveloped by a well-defined perineurium. Higher magnification of the endoneural space of the nerves represented in $\mathrm{A}, \mathrm{C}$ and $\mathrm{E}$ are shown in $\mathrm{B}, \mathrm{D}$ and F, respectively. Large (M) and small myelinated fibers as unmyelinated (A) fibers are present in the endoneural space. Schwann cell nuclei are indicated by *. Note the presence of normal endoneural vessels (V) in the WR and WKY nerves while in SHR collapsed vessels and vessels with endoneural hyperplasia were common. + indicates a large fiber with degeneration signs. Toluidine blue stained. Bar $=50 \mu \mathrm{m}$ for A, C and E and $10 \mu \mathrm{m}$ for B, D and F.

Table 1 shows the fascicular morphometric parameters of the proximal right segments of sural nerve fascicles of WR, WKY and SHR. No differences were observed between segments (proximal and distal) or sides in all strains. The comparison between strains indicated that SHR nerves present a significantly smaller number and density of Schwann cells nuclei when compared to WR and WKY, with no differences between these two.
TABLE 1 - Morphometric parameters of the proximal right segments of sural nerve fascicles of Wistar (WR) WistarKyoto (WKY) and spontameously hypertensive rats (SHR). No differences were observed between segments (proximal and distal) or sides in all strains. * indicates difference compared to WR and \# indicates difference compared to WKY. No differences between WR and WKY were observed. Data expressed as mean \pm standard error of mean (SEM).

\begin{tabular}{cccc}
\hline & WR & WKY & SHR \\
\hline FA $\left(\boldsymbol{\mu m ^ { 2 } )}\right.$ & $71306 \pm 9046$ & $50480 \pm 4990$ & $56710 \pm 2749$ \\
FD $(\boldsymbol{\mu m})$ & $217 \pm 53$ & $195 \pm 18$ & $177 \pm 16$ \\
MF Number & $965 \pm 84$ & $879 \pm 38$ & $968 \pm 27$ \\
MF Density & $13414 \pm 1403$ & $18620 \pm 1684$ & $17358 \pm 574$ \\
SC Number & $53 \pm 14$ & $39 \pm 4$ & $19 \pm 5 * \#$ \\
SC Density & $722 \pm 136$ & $785 \pm 28$ & $333 \pm 74^{*} \#$ \\
\hline
\end{tabular}

$\mathrm{FA}=$ fascicular area, $\mathrm{FD}=$ fascicular diameter, $\mathrm{MF}=$ myelinated fiber, $\mathrm{SC}=$ Schwann cell. Density values expressed as number/fascicular area.

Myelinated fiber area (expressed as $\mu \mathrm{m}^{2}$ ) was significantly larger in WR compared to WKY and SHR (average of $32 \pm 0.6$ vs $27 \pm 1.4$ vs $27 \pm 0.9$ for the proximal right segments, respectively), in all segments and sides. Myelinated fiber diameter values (expressed as $\mu \mathrm{m}$ ) for WR, WKY and SHR followed the area values (average of $5.3 \pm 0.1$ vs $4.9 \pm 0.1$ vs 4.90 .1 for the proximal right segments, respectively) and were also significantly larger on WR in all segments and sides. Myelinated fiber distributions (Figure 3) ranged from 1.5 to $10 \mu \mathrm{m}$ and were bimodal in shape, with peaks at 3.5 and $6.5 \mu \mathrm{m}$ for WR and WKY. Myelinated fiber distribution in SHR was shifted to the left, with peaks at 3.0 and $6.0 \mu \mathrm{m}$, indicating a large percentage of small myelinated fibers in these nerves. 

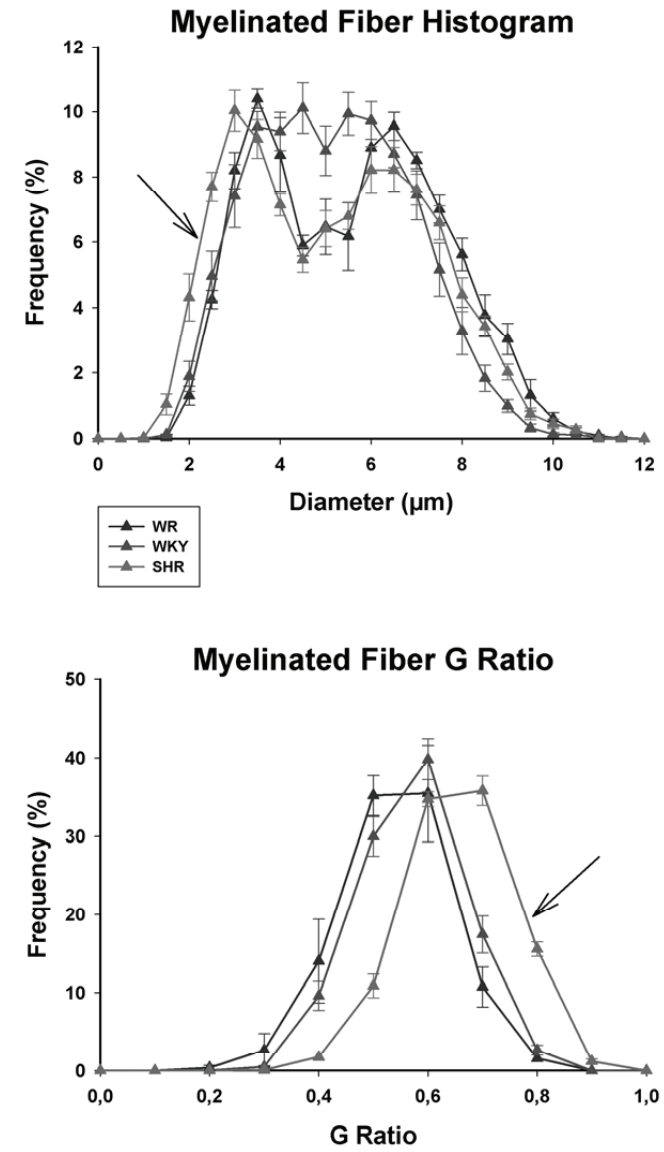

FIGURE 3 - Myelinated fiber diameter (upper panel) and G ratio (lower panel) distributions of the sural nerves in Wistar (WR, black), WistarKyoto (WKY, dark grey) and spontaneously hypertensive rats (SHR, light grey). Note that SHR myelinated fiber distribution is shifted towards the small fiber diameters while the $\mathrm{G}$ ratio distribution is shifted towards larger values.

Nevertheless, myelinated axon area (expressed as $\mu \mathrm{m}^{2}$ ) was significantly larger in SHR compared to WR and WKY in all segments and sides, except the distal right (Figure 4). There was a tendency for the axon diameter values to follow the area averages, attaining a significant difference on the distal left segment (Figure 4).
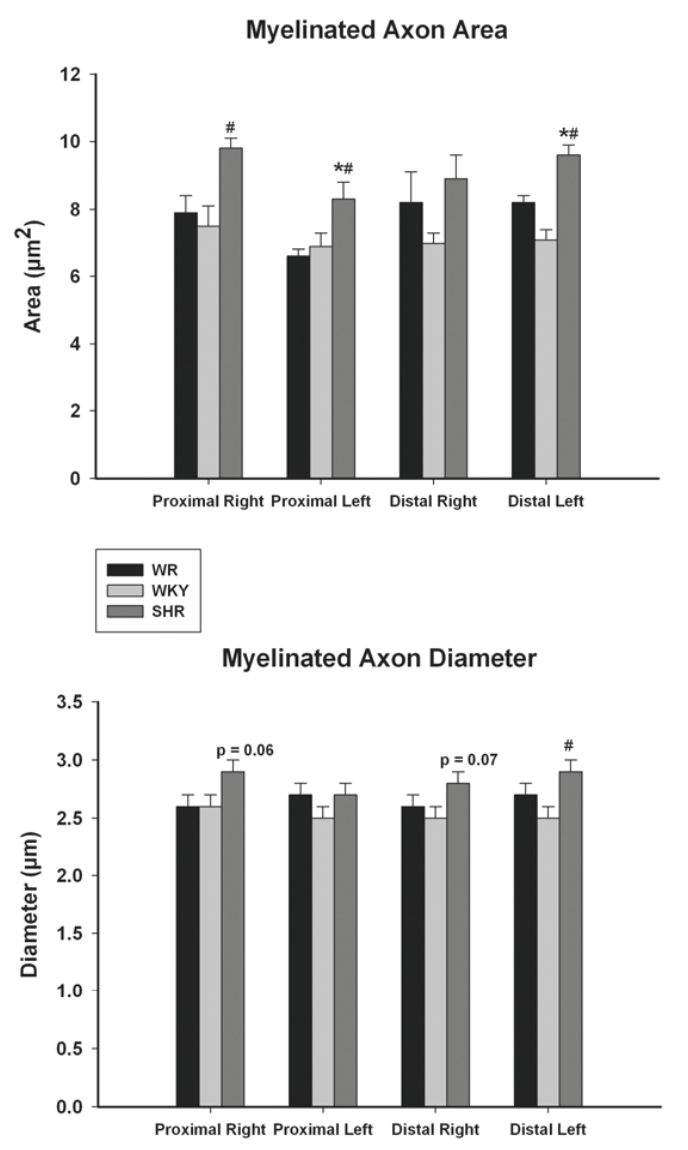

FIGURE 4 - Average area (upper panel) and diameter (lower panel) of the myelinated axons of the sural nerves in Wistar (WR, black), WistarKyoto (WKY, dark grey) and spontaneously hypertensive rats (SHR, light grey). ${ }^{*}$ indicates difference compared to WR and \# indicates difference compared to WKY. P values close to 0.05 are also indicated. No differences between WR and WKY were detected.

Myelinated axon distributions (not shown) ranged from 0.5 to $8.0 \mu \mathrm{m}$ and were unimodal in shape, with peaks at 2.5 for WR and WKY and 2.0 for SHR. SHR distributions were skewed to the right, with a reduced percentage of the peak for small axons (less than $20 \%$ compared to $25 \%$ for WKY and WR), following the average axonal size data. $\mathrm{G}$ ratio average values were significantly larger in SHR (average of $0.6 \pm 0.01$ for the proximal right segments) compared to WR and WKY (average of $0.5 \pm 0.02$ and $0.5 \pm 0.01$ for the proximal right segments, respectively) and the G ratio distributions (Figure 3) were unimodal and significantly shifted to the right on SHR. No differences between WR and WKY were observed. The average myelin area values (expressed as $\mu \mathrm{m}^{2}$ ) were significantly larger on WR compared to WKY and SHR (24 \pm 0.9 vs $19 \pm 0.8$ vs $17 \pm 0.7$, for the proximal right segments, respectively) for all segments and sides. 


\section{Discussion}

The importance of this work lies in the fact that it is a qualitative and quantitative demonstration that the sural nerve morphology is similar between WKY and WR. This is important once future studies on changes in nerve morphology may use WR as the SHR controls. For example, the diabetic neuropathy is well known as one of the most common complication of diabetes and it is usually associated with hypertension in the clinical practice. However, the sural nerve morphometry was not yet investigated in an experimental model of diabetes associated with hypertension and ongoing studies from our laboratory will address this issue. To our knowledge, the present study is also the first morphometric description of the sural nerve in adult WKY, providing morphological support for further functional and electrophysiological studies of the sural nerve in this particular rat strain.

Another important conclusion of the present work is that the average myelinated fiber size (area and diameter) followed the rats' body weight, since animals from the three different strains (WR, WKY and SHR) presented the same age (20 week-old) but WR were significantly heavier and their sural nerves showed significantly larger myelinated fibers. It is well known that peripheral nerve function is significantly affected by maturation and aging and most experimental studies not dealing with aging use the body weight to describe adult animals. However, rats described as adults have weights that vary in a range of about 180 $\mathrm{g}$ to $1000 \mathrm{~g}$ or more ${ }^{6,11}$, what might lead to confusion. Sharma et $a l{ }^{12}$ demonstrated that in rats there is a postnatal growth spurt between 30 and 90 days, as judged by increasing in body weight, which affects myelinated fiber diameter in the peripheral nerves. Jeronimo et $a l .{ }^{6}$ indicated that fiber population distribution is affected by increasing body weigh since at 30 days of age, distribution was unimodal and by 180 days this distribution was established as bimodal. We clearly demonstrated that heavier animals present larger myelinated fibers, indicating the need of buth information, age and body weight in order to correctly understand and interpreter fiber morphometry results.

Some experimental studies involving injury of the sciatic nerve and/or its branches use the same nerve of the opposite side as the control ${ }^{13}$. Our results demonstrated that the sural nerve of the three rat strains (WR, WKY and SHR) are laterally symmetric, allowing the use of the contra lateral nerve as the controls in injury and regeneration investigations. This lateral symmetry was also described for the sural nerve of female Sprague-Dawley rats by Berthold et al. ${ }^{3}$. These authors investigated several morphometric parameters of the sural nerves in female Sprague-Dawley rats from 7 to 76 week-old ages but the comparison between their results and ours is questionable. First, there is no information about the body weight of the Sprague-Dawley rats used in that study and we understand, from our results that this is a determinant for interpreting the myelinated fibers size correctly. Second, the authors used 5\% glutaraldehyde in phosphate buffer for the perfusion (compared to $2.5 \%$ glutaraldehyde in cacodylate buffer in the present study) and a hypotonic phosphate buffer solution for post-fixation (compared to an isotonic solution in the present study). Third, samples were dehydrated in acetone (compared to ethanol in the present study) and embedded in Vestopal W (compared to Embed $\AA$ in the present study). Forth, the authors investigated only the most proximal segment of the nerves while we provide information for proximal and distal segments. Finally, in that study ${ }^{3}$ morphometry was performed manually and fiber size was determined by the aid of calibrated circles, while we used a semi-automated image analysis system, which is more accurate in identifying the small fibers ${ }^{14}$. In the present study, samples of all three experimental groups were histologically processed at once so that they were submitted to absolutely the same experimental conditions throughout the experiments, allowing the morphological comparison without methodological bias or artifacts.

The major morphometric difference between the normotensive strains (WR and WKY) and the SHR is that the hypertensive animals showed a significantly smaller number and density of Schwann cell nuclei (Table 1). Schwann cells present an important whole on the regeneration processes that follow a nerve injury. During the regeneration processes, the endoneural content might be rearranged; being the Schwann cell multiplication rate higher than the fibroblast ${ }^{15}$. Nerves that are experiencing regeneration will have a larger number of Schwann cells due to their augmented duplication rate under these circumstances ${ }^{15}$. The smaller number of Schwann cell nuclei in SHR might interfere with its regenerating ability and further investigations are necessary in order to verify the possible regeneration impairment of SHR nerves.

\section{Conclusion}

Sural nerve morphology is similar between WKY and WR, allowing the use of WR as the SHR controls in morphological investigations involving peripheral neuropathies. 


\section{References}

1. Oyama N, Yagita Y, Sasaki T, Omura-Matsuoka E, Terasaki Y, Sugiyama Y, Sakoda S, Kitagawa K. An angiotensin II type 1 receptor block can preserve endothelial function and attenuate brain ischemic damage in spontaneously hypertensive rats. J Neurosci Res. 2010;88:2889-98.

2. Fritz M, Rinaldi G. Blood pressure measurements with the tail-cuff method in Wistar and Spontaneously hypertensive rats: influence of adrenergic- and nitric oxide-mediated vasomotion. J Pharmacol Toxicol Methods. 2008;58:215-21.

3. Berthold $\mathrm{CH}$, Lugnegard $\mathrm{H}$, Rydmark M. Ultrastructural morphometric studies on regeneration of the lateral sural cutaneous nerve in the white rat after transection of the sciatic nerve. Scand J Plast Reconstr Surg Suppl. 1984;20:1-126.

4. Tomassoni D, Traini E, Vitaioli L, Amenta F. Morphological and conduction changes in the sciatic nerve of spontaneously hypertensive rats. Neurosci Lett. 2004;362:131-5.

5. Fazan VPS, Salgado HC, Reis GC, Barreira AA. Relation between myelin area and axon diameter in the aortic depressor nerve of spontaneously hypertensive rats. J Neurosci Methods. 2005;148:130-6.

6. Jeronimo A, Jeronimo CA, Rodrigues Filho OA, Sanada LS, Fazan VPS. Microscopic anatomy of the sural nerve in the postnatal developing rat: a longitudinal and lateral symmetry study. J Anat. 2005;206:93-9.

7. Alcântara ACL, Salgado HC, Fazan VPS. Morphology and morphometry of the vagus nerve in male and female spontaneously hypertensive rats. Brain Res. 2008;1197:17080.

8. Jeronimo A, Jeronimo CAD, Rodrigues Filho OA, Sanada LS, Fazan VPS. A morphometric study on the longitudinal and lateral symmetry of the sural nerve in mature and aging female rats. Brain Res. 2008;1122:51-60.

9. Auer RN. Automated nerve fiber size and myelin sheath measurement using microcomputer-based digital image analysis: theory, method and results. J Neurosci Methods. 1994;51:229-38.

10. Rushton WAH. A theory of the effects of fiber size in medullated nerve. J Physiol. 1951;115:101-22.

11. Saitua F, Alvarez J. Do axons grow during adulthood? A study of caliber and microtubules of sural nerve axons in young, mature, and aging rats. J Comp Neurol. 1988;269:203-9.

12. Sharma AK, Bajada S, Thomas PK. Age changes in the tibial and plantar nerves of the rat. J Anat. 1980;130:417-28.

13. $\mathrm{Hu}$ P, McLachlan EM. Selective reactions of cutaneous and muscle afferent neurons to peripheral nerve transection in rats. J Neurosci. 2003;23:10559-67.

14. Silva AP, Jordão CE, Fazan VPS. Peripheral nerve morphometry: Comparison between manual and semiautomated methods in the analysis of a small nerve. J Neurosci Methods. 2007;159:153-7.

15. Thomas GA. Quantitative histology of Wallerian degeneration; nuclear population in two nerves of different fibre spectrum. J Anat. 1948;82:135-45.

\section{Acknowledgements}

We thank Mr. Antônio Renato Meirelles e Silva, Experimental Neurology Laboratory, and Ms. Maria Tereza Maglia, Electron Microscopy Laboratory, School of Medicine of Ribeirao Preto for excellent technical support.

\section{Correspondence:}

Valéria Paula Sassoli Fazan

Departmento de Cirurgia e Anatomia

Faculdade de Medicina de Ribeirão Preto

Avenida Bandeirantes, 3900

14049-900 Ribeirao Preto - SP, Brasil

Tel.: (55 16)3602-2501

Fax: (55 16)3633-0017

vpsfazan@yahoo.com.br

vpsfazan@gmail.com

Received: May 10, 2011

Review: July 14, 2011

Accepted: August 11, 2011

Conflict of interest: none.

Financial sources: FAPESP (Fundação de Amparo à Pesquisa do Estado de São Paulo) grant numbers: 2009/50389-6; 2009/167489; 2010/12518-6; CNPq (Conselho Nacional de Pesquisa e Tecnologia) grant number: 300963/2009-2

${ }^{1}$ Research performed at Microscopy and Morphometry Laboratory, Experimental Surgery Division of Surgery and Anatomy Department and Cardiovascular Physiology, Department of Physiology, School of Medicine of Ribeirao Preto, University of Sao Paulo (FMRP-USP), Brazil.

Presented at the XII National Congress on Experimental Surgery of the Brazilian Society for the Development of Research in Surgery-SOBRADPEC 2011 October 26-29, Ribeirao Preto-SP, Brazil. 